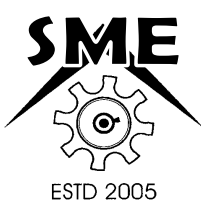

\title{
COMPARISON STUDY OF CONSTANT CURRENT AND ARC OSCILLATION TECHNIQUES ON GTA WELDED AZ31B MAGNESIUM ALLOY JOINTS
}

\author{
* Subravel $\mathrm{V}^{1}$ and Chandrasekaran $\mathrm{V}^{2}$ \\ ${ }^{1}$ Department of Mechanical Engineering, Government College of Engineering, Thanjavur, Tamil Nadu- 613001, India \\ ${ }^{2}$ Department of Mechanical Engineering, Government Polytechnic, Papanasam, Tamil Nadu- 614207, India
}

https://doi.org/10.37255/jme.v15i1pp015-018

\begin{abstract}
The challenges of achieving significant weight reduction in the automobile industry in the context of fuel savings, recyclability and emission reduction has promoted focus on lightweight metals such as magnesium. GTA welding technology is the main welding method adopted for magnesium alloys because of its advantages of utility and economy. Both magnetic arc oscillation and current pulsing techniques resulted in significant microstructural refinement in weld fusion zone. Hence in this investigation an attempt has been made to study the constant current and arc oscillation on tensile and microstructural characteristics of gas tungsten arc welded AZ31B magnesium alloy joints. From this investigation, it is found that the joints fabricated with magnetic arc oscillation having the superior tensile properties compared to constant current welding. The formation of fine grains and higher hardness in fusion zone are the main reasons for the superior tensile properties of these joints.
\end{abstract}

Keywords: Magnesium alloy, GTA welding, tensile properties and Microstructure

\section{Introduction}

Magnesium alloys arouse the interest of the materials field because of good features such as low density, good damping characteristics, dimensional stability, machinability and low casting costs [1]. Magnesium alloys have high stiffness-to-weight ratio, and these applications include automotive, industrial, materials handling and aerospace equipment where there is an obvious need for lightweight materials [2,3] most magnesium alloys are readily weldable using gas tungsten arc (GTA), gas metal arc (GMA), electron beam, laser beam welding processes [4].GTAW process is a widely used material joining process. The quality of GTA welds ranks higher than that of any of the arcwelding processes, due to the reliability, clearance and strength of the weld. However, some processing problems and welding defects such as oxide films, crack, and porosity could easily be caused by the physical properties of magnesium, such as its strong tendency to oxidize, high thermal conductivity, low melting and boiling temperatures, high solidification Shrinkage, and tendency to form low melting point constituents, low viscosity, and high solubility for hydrogen in the liquid state [5].
In general, the severity of a number of weld defects can be reduced if the solidification structure is refined [8]. Magnetic arc oscillation (MAO) is one of the effective techniques for refining the grain structure in the fusion zone of welds. Arc oscillation produces mechanical agitation in the weld fusion zone and breaks down the growing dendrite columns. As the broken dendrites act as nucleating sites and increase the cooling rate, microstructure is refined [9].

Fusion zone grain refinement in aluminum alloy welds through magnetic arc oscillation and its effect on tensile behavior was studied by Janaki Ram et al. [10]. Sivaprasad et al. studied the influence of magnetic arc oscillation and current pulsing on microstructure and high temperature tensile strength of alloy 718 alloy TIG weldments [11]. Effect of mechanical arc oscillation on the grain structure of mild steel weld metal was examined by Mahajan et al. [12]. Grain refinement in magnetically stirred GTA constant current and magnetic arc oscillation on magnesium alloys. Keeping this in mind, an investigation has been carried out to study the effect of constant current and MAO welding processes on tensile and microstructure properties of AZ31B magnesium alloy joints, and the results are revealed in this article. 


\section{Experimental work}

The plates were mechanically and chemically cleaned by acetone before welding to eliminate surface contamination. The initial joint configuration was obtained by securing the plates in position using mechanical clamps. The direction of welding was normal to the rolling direction. The Magnetic arc oscillation equipment is mounted and surrounded with GTAW Torch and interfaced with controller, which monitors the arc oscillation frequency and amplitude. The MAO equipment and controller unit is shown in Figure 1. The photographs of fabricated joints are shown in Figure 2. Argon gas was used as a shielding gas with a constant flow rate of $201 / \mathrm{min}$.

Two joints were fabricated using differen levels of constant current and magnetic arc oscillation. The photographs of fabricated joints are shown in Figure 2.

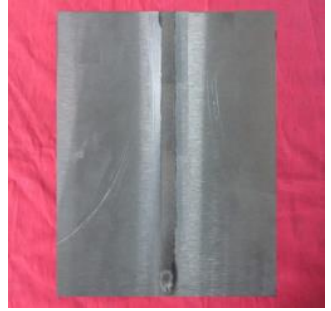

a)

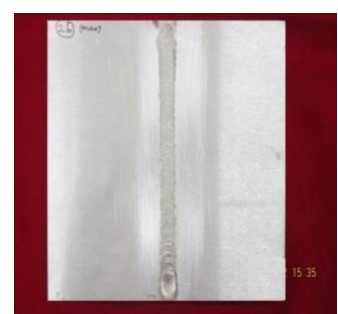

b) MAO
Fig. 1. Photographs of Fabricated joints

Heat input is a very important factor, which affects the bead geometry, mechanical properties and metallurgical properties of weld. Hence, heat input was also calculated and included in the study. In continuous current GTAW process, the heat input per unit length is proportional to voltage and current and inversely proportional to the welding speed.

\author{
Heat Input $=\frac{\mathrm{I} \times \mathrm{V} \times \eta}{\mathrm{S}}$ \\ Where \\ I - Current, Ams \\ $\mathrm{S}$ - Welding speed, $\mathrm{mm} / \mathrm{s}$ \\ $\mathrm{V}$ - Mean voltage, volts \\ $\eta$ - Efficiency of the welding process.
}

Hence, a mean voltage of $18 \mathrm{~V}$ was taken for the heat input calculation. A constant welding speed of $2.25 \mathrm{~mm} / \mathrm{s}$ was used in this investigation. A Vicker's microhardness testing machine (Make: SHIMADZU, Japan; Model: HMV-2T) was used to measure the hardness across the weld cross section with a $0.05 \mathrm{~kg}$ load for a $20 \mathrm{~s}$ dwell time. The specimens for metallographic examination were sectioned to the required size and then polished using different grades of emery paper. A standard reagent made of $4.2 \mathrm{~g}$ picric acid, $10 \mathrm{ml}$ acetic acid, $10 \mathrm{ml}$ diluted water and $70 \mathrm{ml}$ ethanol was used to reveal the microstructure of the welded joints. Microstructural analysis was carried out using a light optical microscope (Make: MEIJI, Japan; Model: MIL-7100) incorporated with an image analyzing software (Metal Vision).

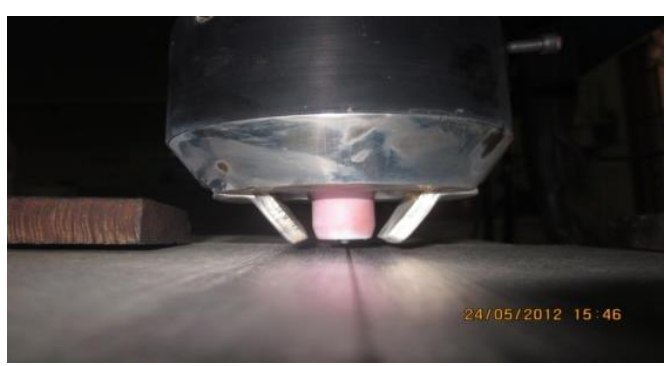

Fig. 2 MAO Equipment

\section{Results and Discussion}

The macrostructure of the joints made with different welding speeds are presented in Figure 3 MAO joints exhibit higher yield strength and tensile strength than CCGTAW welded joints. This is influenced by the weld thermal cycles or in other words by the heat input supplied by the welding process involved. The heat input supplied by the CCGTAW process is relatively higher than that supplied by the MAO processes [Table 1]. These variations of heat input in the welding processes influence the weld thermal cycle and subsequently cause variations in the microstructural features and hardness characteristics. The measured average grain diameter of CCGTAW joints is $36 \mu \mathrm{m}$. Similarly, the measured average grain diameter of MAO joints is $26 \mu \mathrm{m}$, and this also indicates that the reduction in grain diameter is $10 \mu \mathrm{m}$ due to the MAO process. Of the two techniques, the MAO process produces fine grains in the weld metal region compared with CCGTAW processes.

Fine grained microstructures obtained by these arc manipulation techniques on the autogenous have been presented in Figure 4, along with the coarser grained microstructure that is generally observed in CCGTA weld metals. Though there are many sets of oscillation that have resulted in fine equiaxed grains in the weld metal. It is observed that oscillation frequency plays an important role in generating the equiaxed 
grains [kou]. MAO welds were found to have better hardness $(68 \mathrm{VHN})$ compared to those made on CCGTAW joints. The reason for the higher hardness is the grain refinement and equiaxed grains in weld metal.

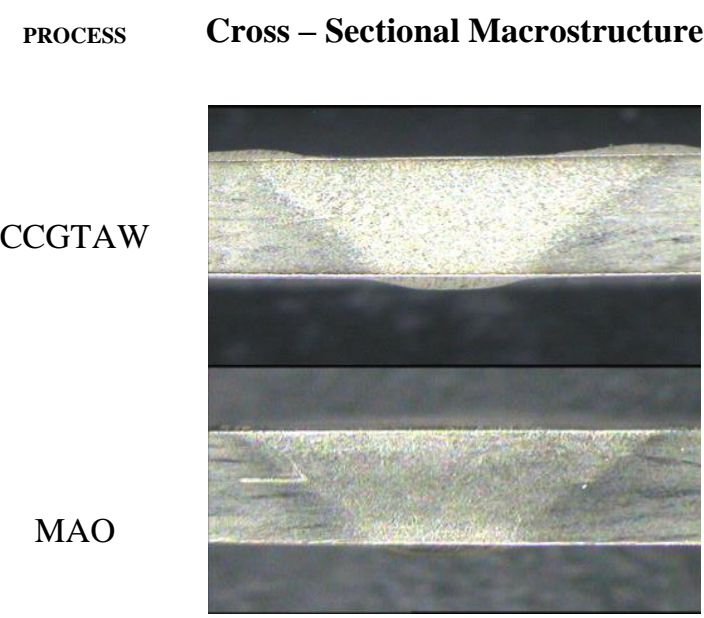

Fig. 3 Bead geometry

Table. 1 Properties in CCGTAW and MAO process

\begin{tabular}{ccccc}
\hline Process & $\begin{array}{c}\text { Heat Input } \\
\mathrm{J} / \mathrm{mm}\end{array}$ & $\begin{array}{c}\text { Yield strength } \\
(\mathrm{MPa})\end{array}$ & $\begin{array}{c}\text { Ultimate } \\
\text { tensile } \\
\text { strength } \\
(\mathrm{MPa})\end{array}$ & $\begin{array}{c}\text { Joint } \\
\text { efficiency } \\
(\%)\end{array}$ \\
\hline CCGTAW & 423 & 156 & 192 & 70 \\
MAO & 355 & 192 & 248 & 91 \\
\hline
\end{tabular}

The tensile testing revealed that there is a marginal improvement in yield strength of the welded joints, due to the use of arc manipulation techniques produces mechanical agitation in the weld fusion zone and breaks down the growing dendritic columns formed during weld solidification. These broken dendrites can act as new nucleating sites leading to refined equiaxed grain structure. The refinement of grain structure in the weld fusion zone should have an impact on the tensile properties of the welded joints.
Process

Cross - Sectional Microstructure

MAO
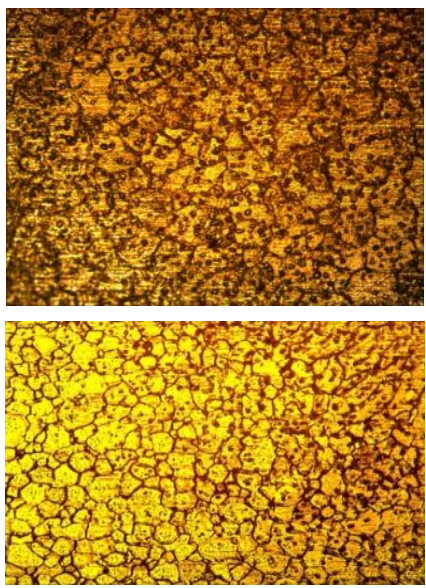

Fig. 4. Fine grained microstructures

\section{Conclusions}

From this investigation, the following important conclusions are derived:

i. Of the two welded joints. The joints fabricated by MAO exhibited higher tensile strength and the enhancement in strength was approximately $21 \%$ when compared with CCGTAW joints.

ii. Lower heat input, finer fusion zone grain diameter, and higher fusion zone hardness may be the reasons for superior tensile properties of MAO joints compared to CCGTAW joints.

\section{Acknowledgments}

The authors wish to place their sincere thanks to University Grant commission (UGC), New Delhi for financial support rendered through Major Research Project No: 39-864/2010. 


\section{References}

1. Manuel Marya A, Louis Hector G and Ravi Verma (2006), "Microstructural effects of AZ31 magnesium alloy on its tensile deformation and failure behaviors", Materials Science and Engineering A, 418: 341-356.

2. Ding $W B$, Jiang $H Y$, Zeng $X Q$ and Li $D H$ Yao S.S (2007), "The surface modified composite w laver formation with boron carbide particles on magnesium alloy surfaces through pulse gas tungsten arc treatment", Applied Surface Science, 253: 3877-3883.

3. Balasubramanian M, Jayabalan V and Balasubramanian V (2008), "Prediction and Optimization of Pulsed Current Gas Tungsten Arc Welding Process Parameters to Obtain Sound Weld Pool Geometry in Titanium Alloy Using Lexicographic Method", Journal of Materials Engineering and Performance, 18:871-877.

4. Balasubramanian TS, Balakrishnan M, Balasubramanian $V$ and Muthu Manickam M A (2011), "Influence of welding processes on microstructure, tensile and impact properties of Ti-6Al-4V alloy joints", Trans. Nonferrous met soc.china, 21: 1253-1262.

5. Kou $S$ and $Y$ Le (1988), "Welding parameter and grain structure of weld metal Metallugical Transactions A", $19 \mathrm{~A}$ -1075 .

6. Padmanaban $G$ and Balasubramanian $V$ (2011), "Influences of Pulsed Current Gas Tungsten Arc Welded Parameters on Mechanical and Metallurgical Properties of AZ31B Magnesium Alloys", Metals and Materials International., Vol.17,No. 5 pp. 831-839.

7. Cornu J (1998), "Advanced Welding System, TIG and Related Processes”, Vol. 3, p. 61, Springer, Heidelberg.

8. Karunakaran N and Balasubramanian V (2011), "Effect of pulsed current on temperature distribution on weld bead profiles and characteristics of gas tungsten arc welded aluminum alloy joints", Trans. Nonferrous mat soc china 21: $278-286$
9. Burden $M H$ and Hunt J D (1974), "Columnar and equiaxed growth: II. Equiaxed growth ahead of a columnar front", J. Cryst. Growth, vol. 22, pp. 109-16.

10. Rajesh Manti, Dwivedi D K and Agarwal A (2008), "Pulse TIG Welding of Two Al-Mg-Si Alloys", Journal of Materials Engineering and Performance, 17:667-673.

11. Koteswararao $S \quad R$ and Madhusudhanareddy $G$ (2005), "Grain refinement through arc manipulation techniques in $\mathrm{Al}-\mathrm{Cu}$ alloy GTA welds", materials science and engineering a 404 227-234.

12. Janaki ramG D and Murugesan R (1999). "Fusion Zone Grain Refinement in Aluminum Alloy Welds through Magnetic Arc Oscillation and Its Effect on Tensile Behavior",Journal of materials engineering and performance 8:513-520.

13. Sivaprasad K, Ganesh $S$ and sundararaman (2007), "Influence of magnetic arc oscillation and current pulsing on fatigue behavior of alloy 718 TIG weldments", materials science and engineering a 448 120-127.

14. Mahajan N S and Biradar (2012), "Effect of Mechanical Arc Oscillation on the Grain Structure of Mild Steel Weld Metal", Transactions of Indian institute of metals 65(2):171-177.

15. Pearce $B$ p and kerrb $H W$ (1981), "Grain Refinement in Magnetically Stirred GTA Welds of Aluminum Alloys", metallurgical transactions $b, 480$--volume $12 b$.

16. Biradar N S and R. Raman (2012), "Grain Refinement in Al-Mg-Si Alloy TIG Welds Using Transverse Mechanical Arc Oscillation" journal of materials engineering and performance, 10.1007/s11665-012-0207-2. 